\title{
Labyrinthe
}

32 | 2009 (1)

Le petit théâtre intellectuel

\section{Épilogue - La vie rêvée des Revuistes}

\section{Renaud Pasquier}

\section{Q OpenEdition}

\section{Journals}

\section{Édition électronique}

URL : http://journals.openedition.org/labyrinthe/3991

DOI : 10.4000/labyrinthe.3991

ISSN : 1950-6031

\section{Éditeur}

Hermann

\section{Édition imprimée}

Date de publication : 19 juin 2009

Pagination : 63-65

ISBN : 978-2-7056-6885-3

\section{Référence électronique}

Renaud Pasquier, «Épilogue - La vie rêvée des Revuistes », Labyrinthe [En ligne], 32 | 2009 (1), mis en ligne le 01 février 2011, consulté le 19 avril 2019. URL : http://journals.openedition.org/labyrinthe/3991 ; DOI : 10.4000/labyrinthe.3991 


\section{ÉPILOGUE \\ La vie rêvée des Revuistes}

\section{Les Revuistes rêvent.}

Ils ont bâti un espace commun, havre au cœur de l'univers, un rafiot voguant entre les rives hostiles de l'Académie et du Marché, qu'ils observent attentivement de leur bâtiment-bunker, poste de guet et de tir, d'où ils distribuent bons et mauvais points. Ils y refont le monde, ivrognes réveillonnant au fond de leur troquet. Affranchis - croient-ils - des contraintes de l'espace, ils le sont aussi de celles du temps : ils revisitent le Passé, prévoient le Futur, et réinventent le Présent. Car ils tiennent que la véritable destination d'une revue est de témoigner de l'esprit de son époque, de raviver la véritable actualité sous la surface stérile du nouveau. Ils croient en la force de l'entreprise collective, qui conduit chacun de ceux qui y participent un peu au-delà, voire à revers, de son propre chemin et aussi peut-être sur un chemin un peu différent de celui qu'il aurait suivi, étant seul; chacun devient responsable d'affirmations dont il n'est pas l'auteur, d'une recherche qui n'est pas seulement la sienne. Ils mêlent leurs voix, croisent les approches, décloisonnent les savoirs. Leurs phrases, libres et innovantes, vont sauver l'Université, la recherche, l'humanité!

Mais le songe n'est pas unanime: d'oniriques divergences se révèlent.

Les uns revêtent l'armure du politique, veulent donner l'assaut aux institutions, porter les revendications, lancer des conquêtes: la revue comme plate-forme révolutionnaire. Les autres utopisent, se voient communauté nouvelle, modèle en acte d'un fouriérisme revivifié s'épanouissant dans l'événement d'une grande rave égalitaire. Enfin d'autres encore croient au revival du combat avant-gardiste: qu'explosent les formes révérées, que triomphe l'expérimentation! Ils fantasment leurs phrases en balles de révolver tirées au hasard dans la foule.

$\mathrm{Ne}$ sont-ils pas tous ridicules et vantards? Et qui les préviendra du caractère peu vénéneux de leurs très verbales interventions?

Quand ils reviennent à la réalité, rivalités et querelles se réveillent. 
Voyez ces deux-là débattre jusqu'à épuisement, et vite tourner en rond dans la vacuité, voire dans l'invective (« vermine! », « verrue! »), jusqu'à ce que soit prononcée la révocation: "Tu n'es pas assez indiscipliné! Tu t'exclus de toi-même de la revue! ». Des polémiques éclatent et des portes claquent. Certains deviendront des adversaires, ils se convertiront, jureront n'avoir en rien changé, s'abandonneront sans réserve au pire révisionnisme. Celui qui vainement voulut être roi et réverbère de la pensée (invraisemblable hurluberlu, s'adressant au pur vide...) émet de sombres verdicts, annonce les ravages d'un avenir déjà révolu: «L L fin arrivera ... elle est proche... Il n'y aura plus d'abonnés, de lecteurs, de public... » À quoi l'optimiste, qui ne voit rien qu'en rose, répond vaticinant: " On se moque du public, défions-le! Ce n'est pas un critère. Et puis si besoin est, nous rallierons le vaste et riant Réseau, le nouvel Éden, l'Icarie reverdie. En vérité je vous le dis! ». L'air sévère, cet autre vérifie les comptes, et tance vertement ces verbeux amateurs qui méprisent les vertus du vrai professionnel, le traitant perversement de vendu qui, de la revue, ne s'intéresserait qu'à l'extérieure enveloppe, à sa structure vendable... Quelle révulsante ingratitude, quel métier, vraiment! Enfin il y a celui qui veut détendre l'atmosphère, égayer les revêches: il feint de ne rien voir, multiplie pauvres blagues, jeux de mots en verlan, calembours un peu verts. Très souvent en vain: la discorde prévaut.

Tempête dans un verre d'eau: les Revuistes hululent, environnés d'universelle indifférence.

Mais l'heure est venue, il est tard. On ramasse les verres brisés et on se quitte bons amis, jusqu'au prochain comité de rédaction. Alors tout recommencera, les rôles seront redistribués, et les Revuistes rejoueront, comme à chaque fois, leur Petit Théâtre Intellectuel...

R. P.

\section{Bibliographie, références, lectures :}

I. « Revuiste » désigne un auteur de revue, mais au sens de « pièce comique ou satirique qui passe en revue l'actualité, met en scène des personnalités » (Petit Robert). En l'occurrence, étant donnés la forme et le propos de notre dossier, détourner le terme ne nous paraît pas incongru. 


\section{Épilogue}

II. Labyrinthe $\mathrm{n}^{\circ}$ 31, dossier « Revues mode d'emploi », été 2008 (ainsi que les trente précédents numéros).

III. Walter Benjamin, "Annonce de la revue Angelus Novus », in Euvres I, Paris, Folio essais, p. 266-273 (deux segments de phrases empruntés, quant à la « destination » de la revue, et quant au statut du « public »).

IV. Maurice Blanchot, écrits politiques 1953-1993, Paris, Gallimard, 2008, p. 103 (deux segments de phrases empruntés, touchant «l'entreprise collective $»)$.

V. Les coups de revolver sont empruntés à André Breton, Second manifeste du surréalisme, éd. Kra, 1930, Euvres complètes, t. I, Paris, Gallimard, coll. « La Pléiade », 1988, p. 783. 


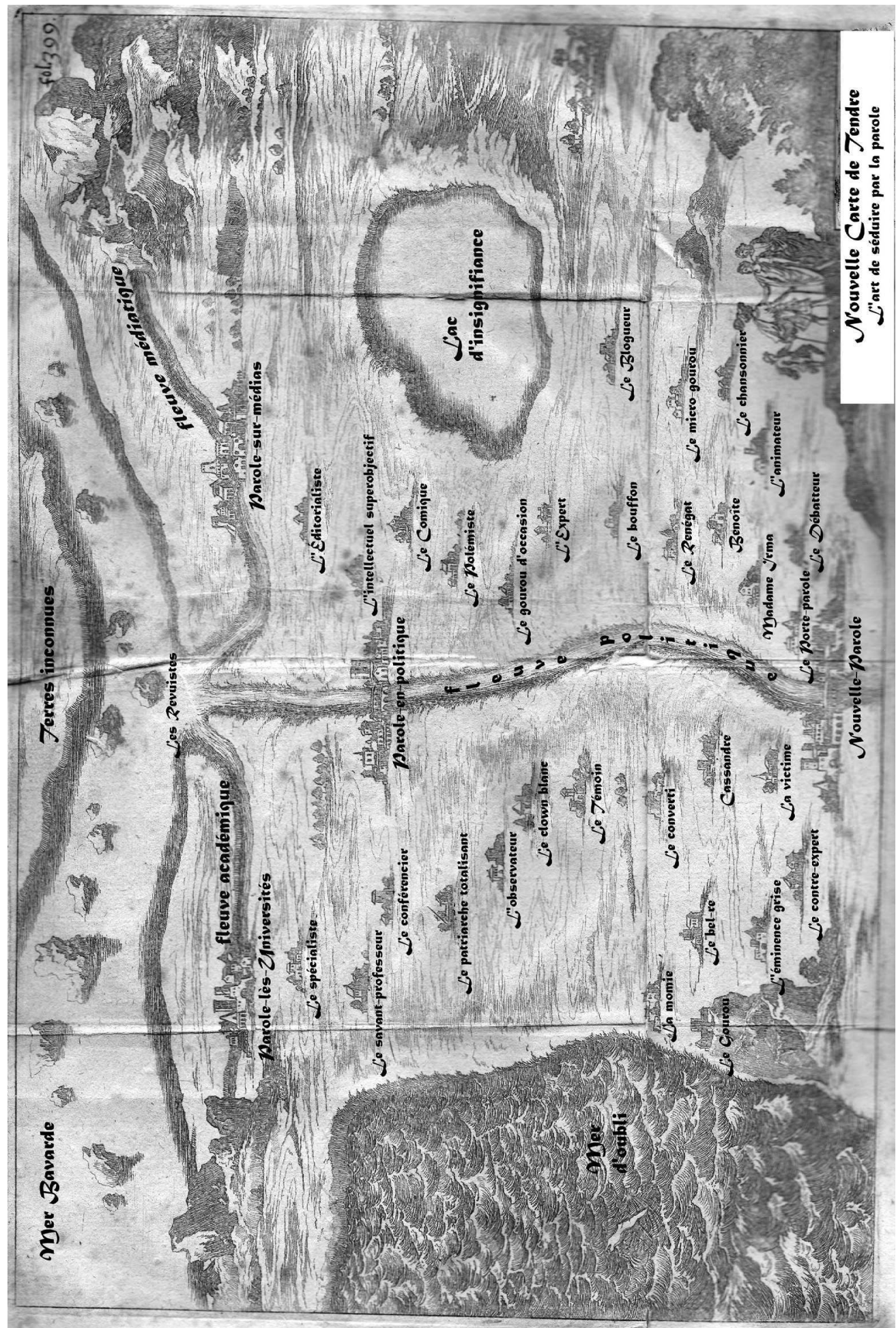

